\title{
Visualizations of the Heavens Before 1700 as a Concern of the History of Science, Medicine and Technology
}

Sonja Brentjes and Dagmar Schäfer

This special issue is dedicated to the knowledge of the heavens in materials and visuals. Within the well-studied field of astronomical and astrological developments, visual and material worlds of knowledge are a largely uncharted field, although such sources are admittedly neither ignored nor unknown (Larsen 1979, 1996). But it is also true that visuals and material properties have been used mainly "to flesh out rather than transform our picture," as Whittow (2018: 69) bemoaned when analysing historical approaches to stelae as sources of knowledge for historical accounts. And in fact a most prominent object of China's history of astronomy-a stone stele erected in 1247 in Suzhou-exemplifies this exact point. This stele was carved with a map that grids the earth into squares in correspondence to heavenly space. Historians have identified the map as the official announcement and tool of the new ruling house of the Song (967-1279) that wished to innovate the administration of the earth and the heavens (Sun 2015). Correlating the visuals to textual sources, they have praised this map as evidence of this era's mathematical and astronomical practices, its cartography and this era's development of the astral sciences. As a stone its role was also to give this knowledge its sense of place and permanence; and through such sense of place it testified to the visual's cultural and regional style. The major narrative, though was set by the texts.

This special issue of NTM is the first result of cooperative work on different forms of visual specimens of the heavens produced, used, transported and transformed across Eurasia and North Africa over several thousands of years. It offers a first inquiry into the material cultures of the heavens and it does so with a broad regional view on the historical debates about knowledge and the sources of the astral sciences: in the recent decade 
researchers interested in astral knowledge have paid increasing attention to the close analysis of the materiality of texts, as well as the instruments of astral knowledge production and representation such as counting rods or astrolabes. This research, we understand, has brought back to attention the central role that object-culture-things, their materials and visuals-played in many past cultures of the world.

To unveil what can be known about past approaches to the heavens from materials and visuals is no mean feat: it asks for transdisciplinary methods, new forms of collaboration and new methods-and for a view that overcomes the boundaries drawn by academic institutional histories. Since the early twentieth century historians of science compared, for instance, Arabic with Greek, Persian, or Sanskrit mathematical or astronomical texts and/or data; tackled Chinese, Latin and Greek languages of cosmology and practical approaches. Yet they left materials and visuals largely untouched, and even if they relied on regional specialists, who looked locally and often within distinct language groups for relationships, they were not necessarily interested in the "Western" and "modern" category of sciences. Aesthetics and methods of art history and studies have only just been resurrected from an often essentializing seemingly cultural discourse informed by nineteenth-century national line drawings and European distinctions between "India," "China," "Mesopotamia", "Egypt" or "Africa". Objects and visualizations of the heavens fulfilled an important function in the boundarydrawing, because as symbols of the power of the ruling house they represented high elite knowledge. Due to this approach they were essentialized as emblems of "culture" and high civilisation, if not high sciences. The objects of the heavens became tools to define the developmental stage of such a culture and its "sciences". However, against the frequently rigid regimes of geographic attributions of objects to certain places and times, many objects are nowadays elsewhere and thus serve other functions restructuring their emblematic meaning. On top of that, different levels of expertise are required to include objects and visuals systematically into a research program-altogether constituting an enormous impediment for researchers now when studying the visual and material worlds of the heavens.

In various regions of the world, academics have approached visual and material sources differently when studying the heavens. In China historians and archaeologists have regularly celebrated objects as important sources for the history of astronomy, substantiating firsts and discoveries. Other regional historiographies tended to include objects mainly when texts were found wanting-or did not consider them at all. Given the rather auxiliary status of objects and visuals in the study of astronomy and astrology, these two disciplines and the heavens remained more or less a matter of art history, while conversely, historians of science often mainly cannibalized art 
historical and museum-related work. Materials and visuals, like texts, are significant though undeniably equally ambiguous informants-as several contributions in this volume illustrate: their meaning relies not on translation but on interpretation, and visual or material reference points that have to be carefully contextualized. All too often researchers rely here on their individual access rights and capacities of time and space. Such limitations may apply to texts as well, yet probably on a different scale.

Digital means offer here impressive new opportunities. Hence, we are convinced that the virtual bringing together of objects in databases will further challenge the histories that we tell about the places and times of objects and visuals-whether or not they travelled differently than texts or concurrently, how they were broken apart, re-assembled or re-combined to make sense of the heavens above. Even today we can see that materials and objects might have carried contents across linguistic boundaries, where texts failed. Equally we may see that communities continued object and visual traditions long after they may have adapted language and writing. Like texts, visuals and materials could remain the exclusive property of some groups, though not necessarily the same.

Within such new assemblies one important challenge is to develop the languages that describe materials and visuals. Both are neither clear-cut nor methodologically well developed in the historical study of astral sciences. Additionally, objects and the visual and material knowledge contained in them is often silently translated into a marker of culture-such as Chinese, Indian or Egyptian-while in fact their geographic provenance and history is far from clear. The sheer weight of a stone stele seems to ground Chinese knowledge and its cultural expression firmly into time and space. And yet we have to ask, why did this star map end up in the garden city of Suzhou more than $150 \mathrm{~km}$ away from the Song capital of Ling'an (modern Hangzhou) - in a culture where knowledge about the heavens was exclusively reserved for the emperor and his astronomical staff. And: who was permitted to create and receive rubbings from such a stele in 1247 ?

The distinctive material properties of the quality of texts and objects has contributed particularly in comparative work to arguments about origins and differences in scientific approaches and cultural expressions thereof. Among the many cases in point, we may exemplify on the media theorist and anthropologist Jack Goody, who prominently took changes in the modes of communication-mainly a move from visual and oral forms of expression to literacy and the alphabet-as markers of the development of abstract thought, the accumulation of knowledge and "enlightened" scientific and technological change. When propagating connectivity across the Eurasian continent, Goody thereby identified major differences between 
the literate cultures of Eurasia and orally oriented cultures in Africa-and left its visuals and materials almost entirely out of sight (Goody 1968).

The multiple levels of boundary drawings (between regions, objects, and visual repertoires) that informed Goody and were mobilized by him in his analyses have been addressed by researchers ever since. Goody's approach to the cognitive capacities of humans to interpret material, textual and visual properties was found wanting and historians have become increasingly aware of the consequences of such an approach: that they have given primacy to texts over objects in the study of Arabic influences that shaped European medieval astral knowledge just as they have emphasized the multiplicity of visual culture in places such as Khotan or Dunhuang. Research thus argued within a reductionist view on knowledge forms and formats when addressing crucial questions of transmission, circulation or exchange-a multiple origin quest based solely on texts, or on translations as major form of exchange rather than adaptation, mimicry and other forms of creative change. The contributions in this issue probe the postulated disparity Goody addressed with reference to knowledge of the heavens, which was an important stimulus for many societies as they inquired the phenomena of the heavens (rain, snow, comets) and reflected on time, constellations and orders on heaven and earth.

Over the course of the last decade the history of science has slowly but inevitably conceded to the multifarious influences that affect scientific change, in particular including visuals and material properties to review such issues. Among the many turns, one of the most influential has shown how much crafts and practices (in)formed scientific thinking. Even for those who agree, for now, that the relation of science and daily practices must always be seen as reciprocal (and that hence any attempt of a chronology might be a chicken and egg question), the lasting effects that such views have for any comparative assessment cannot be denied. Expert groups have dealt differently with the challenges posed by objects and texts when studying their regions of the world, thus framing the corpus and the historiography on which we stand today. The Needham project on Science and Civilisation in China, for instance, brought together different levels of experts on China who paid a lot of attention to connections between Europe and East Asia as well as the role of South and Southeast Asia, the Middle East or Africa's North. Though many of these notions were speculative, researchers in the late twentieth century increasingly focused on comparing one or two regions of which Europe was always one. As for other regions, research of the differences and similarities that may have shaped the development of astral sciences across the European territories, Asia and the African North must be understood as the result of an academic landscape emerging against twentieth-century nation-states, cold 
war politics and economic globalization. Addressing such impediments and biases then is precluded by the ability of the researcher to review an object's origin as well as to situate its "Sitz im Leben" in relation to such overarching methodological concerns.

Having started the enterprise with building first a large-scale visual database reaching across all of Eurasia and North Africa, we quickly learned that the flows of astral visual forms and formats with their concomitant epistemological, symbolic and social qualifiers took highly different directions, focusing, in numerous instances, primarily eastwards due to three main historical processes: the extension (in today's geographical language) of different forms of Buddhism from northern India to China, Japan and South East Asia; the spread of Sumerian and subsequently Akkadian names and insignia of heavenly goddesses and gods as well as those of weather phenomena and the Underworld to northern Indian and central Asian gold and silver coins, murals, and various ritual performances; and the emergence of various successor states of Alexander's empire that Hellenized large parts of the ancient world up to central Asia and northern India. Later religious, political and military conflicts in the Roman empire drove Jewish and Christian communities eastward. These various events and processes brought cosmological beliefs, calendrical terminology, astronomical models and parameters such as the Babylonian zodiacal signs, planetary iconography, Indian cardinal divinities and much more from the Mediterranean, the ancient Near East and ancient northern India into every corner of East, South and South East Asia.

These long-distance movements, adaptations, integrations and transformations of visual specimens of knowledge about the heavens raise questions about how intellectual, artistic, religious, economic and political factors contributed to changes of style, social and cultural functions, material used for the representation, or matter of scale and scope.

Thinner and shorter flows of visual material in forms of tables, diagrams, sketches, pictures, murals, reliefs, figurines, sculptures, mosaics, ritual robes, swords, bone pillows or carpets moved north, south and west. Some of these flows are better known to historians of science, medicine and technology studying parts of Europe and the Middle East such as the various acts of translation between the sixth and thirteenth centuries of texts, images and practices in astrology, astronomy, natural philosophy and alchemy. But even here, visual forms, such as images, sculptures, figurines, dishes, coins and other material objects, have so far remained mainly within the purview of historians of art. Other such middle-range flows of knowledge, practices, practitioners and objects connected in particular central Asia and northern regions of what is today China or the Mediterranean and ancient Iran. These areas and their processes of change and mobility 
are rarely discussed among historians of science, medicine and technology, except for some who study early Imperial China.

Building a database shows that some object classes with heavenly representations did not move across entire continents. Surprisingly, in some periods and regions, even coins moved only across middle-distanced spaces. Such differences between distribution patterns challenge our current models of knowledge transmission, which too often focus on books, whether handwritten or printed, and assume prevalently binary relationships between a knowledge source and its actors and a target with its actors, for example, a translator or a reader. Focusing on objects made from different materials for different purposes and carrying different visual formats representing the heavens such as star maps, registers of data, symbols or complex combinations of pictorial forms highlights that processes of knowledge transfer, transformation and re-appropriation often took place in series of re-interpretations, acts of recycling and social re-positionings, where parts of the encountered and embodied forms of knowledge were misunderstood, discarded or realigned. This seems to indicate that distance was not a significant impulse for processes of knowledge transmission, in contrast to some interpretations of such processes during the early modern period offered in studies of texts and medical products. Thus, an important question here is whether the relative independence of the transmission of heavenly knowledge from distance is specific to this kind of knowledge.

A third set of objects documented in our database remained stationary and locally fixed. This applies in particular to decorations of tomb or cave ceilings and murals, grave goods or objects of local worship and thus reflects the specificity of their identity, message or format. In the recent decades the enormous investment in East Asia into infrastructures has brought forth new materials that pose important questions on the social and use-life of objects, especially in terms of epigraphic habits (MacMullen 1982) but also with regard to the traveling of visual formats, their relation to textual information or the actual audiences that such imagery had, such as the rulers, gods, the public or the deceased her/himself. Tansen Sen (1999), for instance, has brought to the attention of international research a set of zodiacal imagery from a tomb located in the territory of the then-ruling Liao dynasty (r. 916-1125) in northern China. Placed on the ceiling as a mirror image only correctly seen from above, Sen and other researchers have identified this zodiac cycle as influenced by Buddhism as well as Islamic traditions. Many questions emerge concerning not only the traces of knowledge circulation that may have informed the tomb builders so far away from the geographic origins and contemporary hotspots of Buddhism and Islam. Research has furthermore not yet identified why the imagery left no traces of the Chinese Zodiac culture which goes back to the East- 
ern Han dynasty (r. 25-220), prospered in the Sui (r. 581-618) and Tang (r. 617/18-907), declined in the Five Dynasties (r. 907-960), but revived forcefully in the middle and late Northern Song dynasty (r. 960-1127) that had all ruled this region. Do these tombs represent a minor group of migrants or had all adapted their view on the heavens by that time? The material culture of the heavens, as anthropologists have also shown, could change dramatically because of political interferences or environmental and resource changes, but equally arguments have been made that humans actually adapted their material environment, objects and visuals slowly in relation to the changes propagated in elite texts.

What a continuity of visuals, material usages and aesthetics may have done to the view of above (the heaven or sky) is one of the many methodological issues tackled by researchers in this volume. Answers in form of patterns emerged, because researchers were able to contextualize information broadly. Zodiacal figures, for instance, thus far have not been found in southern China during the twelfth century in either format, whereas earlier in the eleventh century, when the same ruling house (the Song) governed East Asia's coastal regions, such configurations have been found. To compare such information nowadays requires careful research across institutions and regions where the sculptures, figures and murals are stored. Much could be said about this case alone, but central here is that the cases of zodiacal representations exemplify how a joint data-project can help comparison across modern institutional and political borders and allow the researcher to consider that, similar to the opening case of the Suzhou stone stele, a local fixation may not necessarily signify that the visual formats were stationary, but that their material hosts may have caused their stationary life cycle. The main question in such cases concerns precisely this relationship between material and visual properties of knowledge of the heavens, a relationship that art historians and archaeologists for some regions of Eurasia consider irrelevant for understanding mobility and immobility of visual forms.

The project set up at the Max Planck Institute for the History of Science aims to enable researchers to re-view the geographic, disciplinary and any other boundary drawing that marks current historiographical practices. As the papers presented in this special issue indicate in many cases historians of astral sciences have to overcome impediments when attempting to systematically and conceptually work with visual specimens and when studying the developments of astronomy and astrology across Eurasia and North Africa beyond the modern political world. The first two papers by John Steele and Daniel P. Morgan address the methodological and material problems we need to consider and engage with for achieving an inclusive manner of history writing. They highlight at the same time the profound 
differences in materiality and epistemology that exist between their knowledge cultures and what we gain by including them in our cross-continental reflections. Such conversations show that the current binary pair of local and global is unsuitable for the study of large-scale processes of knowledge mobility and relocation.

The third paper by Antonio Panaino focuses less on the historiographical and methodological aspects of including visual specimens into the historical study of knowledge about the heavens than on the inclusion of an entire region over more than a millennium into the history of science, medicine and technology from which it remained widely isolated due to the methodological focus on languages and the accepted models of knowledge transfer. Renewed attention to the various chronological, conceptual and technical aspects of the scarce material that survived from Iranian cultures promises a new chance to integrate this important region into a more inclusive approach to the history of astral knowledge.

The four remaining papers present special case studies. Three of them by Satomi Hiyama, Marion Frenger and TV Venkateswaran focus on special corpora of regionally limited spread and existence across time. Hiyama's paper shows that Buddhist cave paintings in central Asia and northern China can teach us important lessons about the differences in appropriation of cosmological doctrines from India in different cultural environments. Frenger argues that decontextualized Buddhist and Brahmanic fragmentary sculptures without any textual information, when analyzed on their own terms, can offer important tools for re-envisioning the impact of Hellenistic knowledge, culture and politics in north-western India, Afghanistan and Pakistan. Venkateswaran's analysis of inscriptions on temple walls in southern India proves that they are an important documentary source for calendrical practices, the social standing of astrologers and the importance of astral knowledge for courtly policies. The fourth paper by Shi Yunli suggests that the analysis of visual features of texts can help to identify work practices of foreigners in a Chinese environment, uncover goals of illustrating technical literature and specify learning efforts of newcomers to an unknown knowledge culture, which the written and printed text cannot help to discover because of its greater opacity.

All four case studies highlight that a systematic investigation of visual specimens representing knowledge of the heavens will provide us access to hitherto unknown pages of the history of astronomy and astrology that only surface through such cross-disciplinary studies of objects that are traditionally the domains of art historians and archaeologists. All authors carve out new ground for debates about the attributes and attributions that they investigate by providing reflections on how the possibilities of rearranging materials in new views may spur new research issues. Epigraphic 
habit in Indian temples thus poses new questions about calendric practices and the understanding of eclipses as digital methods as we are able to map changing visual representations to, for instance, changing modes of computing time. Or we can see how by changing references points-what to compare as a "similar" object or distinct-challenges an object's anchoring in time and place. Because researchers now can access visuals virtually, the sources of our historical actors-Jesuits in China drawing from European literature, Mesopotamian astrologers, Han literati, Buddhist monks, Brahmins or Vijayanagara rulers - need to be and can be reassessed. Modern visual mapping technologies allow us to trace the itineraries of Sumerian cosmology over the central Asian plane or allow us to assemble the composition of astral deities in north-western India across different temple sites. In this way, regionally more sophisticated geographies emerge of the deliberate or intuitive choices and decisions made by scholars, rulers or craftsmen who convert what was perceived and conceived from above into spectacular pictures by assigning colors, adjusting contrast, and actively composing viewpoints, balancing the desire for an aesthetically pleasing representation with the need for a-for their times-valid meaning.

Funding Open Access funding provided by Projekt DEAL.

Open Access This article is licensed under a Creative Commons Attribution 4.0 International License, which permits use, sharing, adaptation, distribution and reproduction in any medium or format, as long as you give appropriate credit to the original author(s) and the source, provide a link to the Creative Commons licence, and indicate if changes were made. The images or other third party material in this article are included in the article's Creative Commons licence, unless indicated otherwise in a credit line to the material. If material is not included in the article's Creative Commons licence and your intended use is not permitted by statutory regulation or exceeds the permitted use, you will need to obtain permission directly from the copyright holder. To view a copy of this licence, visit http://creativecommons. org/licenses/by/4.0/.

\section{References}

Goody, Jack 1968. Literacy in Traditional Societies. Cambridge: Cambridge University Press. Larsen, Mogens Trolle 1979. The Tradition of Empire in Mesopotamia. In: Mogens Trolle Larsen (ed.). Power and Propaganda. A Symposium on Ancient Empires. (Mesopotamia Copenhagen Studies in Assyriology 7). Copenhagen: Akademisk Forlag: 75-103.

Larsen, Mogens Trolle 1996. The Conquest of Assyria: Excavations in an Antique Land, 1840-1860. New York: Routledge.

MacMullen, Ramsay 1982. The Epigraphic Habit in the Roman Empire. American Journal of Philology 103 (3): 233-246.

Sen, Tansen 1999. Astronomical Tomb Painting from Xuanhua: Mandalas? Ars Orientalis (29): 29-54.

Sun, Xiaochun 2015. Chinese Constellations and Star Maps. In: Clive L. N. Ruggles (ed.). Handbook of Archaeoastronomy and Ethnoastronomy. New York: Springer: 2051-2058. 
Whittow, Mark 2018. Sources of Knowledge; Cultures of Recording. Past E Present 238 (13): 45-87. https://doi-org.eres.qnl.qa/10.1093/pastj/gty028.

Publisher's Note Springer Nature remains neutral with regard to jurisdictional claims in published maps and institutional affiliations.

Sonja Brentjes

Max Planck Institute for the History of Science

Boltzmannstraße 22

14195 Berlin

Germany

brentjes@mpiwg-berlin.mpg.de 